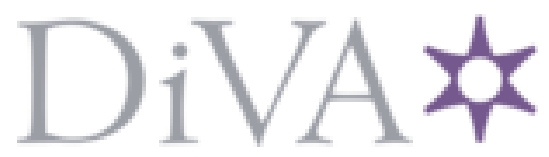

http://www.diva-portal.org

This is the published version of a paper published in Nordic Pulp \& Paper Research Journal.

Citation for the original published paper (version of record):

He, J., Engstrand, P., Björkqvist, O., Zhang, W. (2013)

Techno-economic evaluation of a mechanical pulp mill with gasification.

Nordic Pulp \& Paper Research Journal, 28(3): 349-357

Access to the published version may require subscription.

N.B. When citing this work, cite the original published paper.

Permanent link to this version:

http://urn.kb.se/resolve?urn=urn:nbn:se:miun:diva- 17702 


\section{Techno-economic evaluation of a mechanical pulp mill with gasification}

\section{Jie He, Per Engstrand, Olof Björkqvist and Wennan Zhang}

KEYWORDS: Gasification, Mechanical Pulping, Power Generation, Biomass Residues, ASPEN Plus

SUMMARY: Mechanical pulping processes, including thermomechanical pulp (TMP), groundwood (SGW and PGW), and chemithermomechanical pulp (CTMP) processes, each have a very high wood-to-pulp yield. Producing pulp by means of these processes is a prerequisite for paper (such as printing paper and paperboard) grades requiring high printability and stiffness. However, mechanical pulping processes consume a great amount of electricity, which may account for up to $40 \%$ of the total pulp production cost. In mechanical pulping mills, wood (biomass) residues are commonly utilized for electricity production through an associated combined heat and power (CHP) plant. This techno-economic evaluation deals with the possibility of utilizing a biomass integrated gasification combined cycle (BIGCC) plant in place of the CHP plant. Implementing BIGCC in a mechanical pulp production line might greatly improve the overall energy efficiency and cost-effectiveness, especially when more biomass from forest (such as branches and tree tops) is available. When the fibre material that negatively affects pulp properties is utilized as a bioenergy resource, the overall efficiency will be further improved. A TMP+BIGCC mathematical model is developed with ASPEN Plus. By means of modeling, three cases are studied:

1) adding more forest biomass logging residues in the gasifier,

2) adding the reject fibres in the gasifier, and

3) decreasing the TMP-specific electricity consumption (SEC) by up to $50 \%$.

For a TMP+BIGCC mill, the energy supply and consumption are analyzed in comparison with a TMP+CHP mill. The production profits are evaluated.

\section{ADDRESSES OF THE AUTHORS:}

Jie He (jie.he@miun.se),

Per Engstrand (Per.Engstrand@miun.se),

Olof Björkqvist (Olof.Bjorkqvist@miun.se) and Wennan Zhang (wennan.zhang@miun.se), Department of Applied Science and Design, Mid Sweden University, Sundsvall, SE-85170, Sweden

Corresponding author: Wennan Zhang

\begin{tabular}{ll}
\hline \multicolumn{2}{l}{ Abbreviations } \\
\hline bdt & bone dry tonne \\
BIGCC & biomass integrated gasification combined cycle \\
CHP & $\begin{array}{l}\text { combined heat and power with boiler-steam } \\
\text { turbine system }\end{array}$ \\
CIGCC & coal-based integrated gasification combined cycle \\
CTMP & chemithermomechanical pulp \\
daf & dried and ash free \\
DDB & double declining balance depreciation method \\
DFBG & dual fluidized bed gasifier \\
DH & district heating \\
FSCN & Fibre Science and Communication Network
\end{tabular}

\begin{tabular}{ll} 
IRR & internal rate of return \\
O\&M cost operation and maintenance cost \\
PFI & Pulp and Paper Research Institute \\
PGW & pressurized groundwood \\
PM & papermaking \\
SEC & specific electricity consumption \\
SECR & reduction of SEC, $\%$ \\
SGW & stone groundwood \\
TMP & thermomechanical pulp \\
tpy & tonne per year \\
\hline
\end{tabular}

Paper mill with thermomechanical pulp (TMP) process has a very high wood-to-pulp/wood-to-paper yield (>95\%), but consumes a large amount of electricity (about 2.5 MWh per tonne of pulp). As a TMP-process normally is integrated with paper production, and electricity consumed in the refining process is simultaneously utilized to obtain steam and hot water, one can say that the electric power is used twice, first to produce the pulp and then to produce steam for drying paper. Chemical pulp mill producing bleached softwood kraft can be self-sufficient in both heat and electric energy use, but has a low wood-to-pulp yield (45\%). Lignin, extractives, and most of the hemicellulose, which make up about half of the pulpwood, are dissolved to become black liquor, which is incinerated to produce steam and electricity. This way, black liquor has become the most important bioenergy source in the pulp and paper industry and also the largest bioenergy source presently in Sweden. A focus has been on the technology development on black liquor gasification for the cogeneration of heat and power (Berglin, Berntsson 1998; Eriksson, Harvey 2004; Harvey, Facchini 2004; Holmberg, Gustavsson 2007a; Naqvi et al. 2010; Naqvi et al. 2012). On the other hand, very little development has been accomplished for gasification-based cogeneration of heat and power in the context of a TMP mill.

The pulp quality possible to achieve by means of mechanical pulping processes is a prerequisite for producing printing paper and paperboard, especially due to their important functional properties of these products, such as printability and stiffness. In the Nordic countries, a larger share of paper production uses mechanical pulp than anywhere else in the world (Ruohonen, Ahtila 2011). Energy-efficient refining has been an important research subject for a long period of time (Engstrand et al. 2003; Engstrand et al. 1989; Gorski et al. 2010; Höglund et al. 1994; Muhic et al. 2010; Norgren, Höglund 2009; Sabourin 1999). The institute of Fibre Science and Communication Network (FSCN) at Mid Sweden University, together with Scandinavian forest and supplier companies, the Pulp and Paper Research Institute (PFI), and other Scandinavian universities, is working with a large research program with the goal of showing how to design the TMP and CTMP mills of the future. It is possible to reduce $50 \%$ of the specific 
electricity consumption (SECR). Today, a large part of biomass such as the logging residues (branches and tree tops), is normally not utilized as a source of bioenergy. Furthermore, the possibility of utilizing the fibre material that has negative influence on the final product properties as a source of bioenergy has not been evaluated. Normally, only the bark, shavings, and bio-sludge are utilized in present bark boilers of CHP systems of mechanical pulp mills. It is also important to explore the potential of achieving cost-effective and energy-efficient heat and power production from those biomass residues, especially for a TMP mill.

The back-pressure system with a steam turbine is popular in TMP mills. This system has low electricity generation efficiency less than $30 \%$. In comparison, a gas turbine system has the efficiency up to $40 \%$, while a biomass integrated gasification combined cycle (BIGCC) may reach the efficiency up to $50 \%$.

Implementing BIGCC to a TMP mill may create significant potential for self-sufficient electricity and for more economic benefit to the mill.

Ong'iro, et al. (1996; 1995) developed several models to study the effects of design and operation parameters on the energy efficiency of a coal-based integrated gasification combined cycle (CIGCC) and on the efficiency of an integrated gasification humid air turbine cycle, respectively. A thermodynamic model of a combustion power plant was also developed with ASPEN Plus to evaluate the thermodynamic feasibility of the cogeneration with a higher ratio of electricity to heat. Using ASPEN Plus, Emun et al. (2010) simulated a CIGCC, and pointed out that the overall energy efficiency can approach to 45\%. Eriksson and Kjellström (2010) performed a techno-economic analysis over a CHP process integrated into a wood-based ethanol production process. They claimed that the utilization of the residues from an ethanol production process through a CHP system was the most promising of all. For a CHP plant, the annual fixed operation cost was assumed to be $2 \%$ of the total investment, and the capital investment was only about $10 \%$ of the total cost of a wood-based ethanol production plant (Eriksson, Kjellström, 2010).

In the present study, a BIGCC model, special for a combined TMP+BIGCC system, is set up with ASPEN Plus. The syngas is produced from the biomass residues, collected at a pulpwood logging site, and the rejects from a TMP mill, by means of a dual fluidized bed gasifier (DFBG) system. A BIGCC system consists of a gas- and steam-turbine cycles. The obtained syngas will fuel the gas-turbine cycle, while the steam used in a papermaking (PM) process is withdrawn from the coupled steam cycle.

A techno-economic analysis is performed on the basis of this modeling. Three cases are studied:

1) adding more forest biomass logging residues in the gasifier,

2) adding the reject fibres in the gasifier, and

3) decreasing the TMP-specific electricity consumption (SEC) by up to $50 \%$.

The production profits are evaluated. The economic benefit from a TMP+BIGCC mill is compared with that from a TMP+CHP mill.

\section{Process and Modeling Method}

\section{TMP+PM}

A typical flowsheet of TMP process can be found in the literature (Sundholm 1999). Some of the input data to this model are from a TMP+PM mill, Hallsta, Holmen Paper, Table 1 (Pettersson 2005).

Biomass residues from a TMP+PM mill are traditionally utilized through a CHP plant to supply the mill electricity and steam. The original CHP plant is intended to be replaced by a BIGCC plant.

Available biomass residues from a TMP plant are significant and include: 1) logging residues, amounting to $30 \%$ of the tree; 2) bark, $12 \%$ of the stem, 3) bio-sludge, $2 \%$ of the pulpwood, and 4) reject fibres, $10 \%$ of the pulp. Fig 1 implies that 0.7 tonne of biomass residues are available from the production of each tonne of pulp. Additional biomass (including peat) can be gained from other applications such as the production of chemical pulp, construction of woody structures, etc.

\section{BIGCC and its implementation in a TMP mill}

Coal-based IGCC technology has been effectively commercialized. Biomass-based IGCC technology, however, is at a pre-commercialization stage, with syngas cleaning as a key issue. In this study, DFBG, an indirect gasifier, is chosen for biomass gasification. It consists of a bubbling fluidized bed gasifier and a circulating fluidized bed combustor.

Table 1. Outline of a thermal mechanical pulping and papermaking line (Pettersson, 2005).

\begin{tabular}{|c|c|c|}
\hline & TMP & PM \\
\hline $\begin{array}{l}\text { Yield } \\
\text { Pulpwood with Bark } \\
\text { Pulpwood } \\
\text { Biomass Residues } \\
\text { Electricity consumption }\end{array}$ & $\begin{array}{c}230000 \mathrm{t} / \mathrm{yr} \\
250000 \mathrm{t} / \mathrm{yr} \\
220000 \mathrm{t} / \mathrm{yr} \\
2.5 \mathrm{MWh} / \mathrm{bdt} \text { pulp }\end{array}$ & $\begin{array}{l}\text { 3.9a MWh/bdt pulp } \\
0.75 \mathrm{MWh} / \mathrm{bdt} \text { pulp }\end{array}$ \\
\hline \begin{tabular}{|rr} 
Steam & $\begin{array}{r}\text { production } \\
\text { consumption }\end{array}$ \\
\end{tabular} & $\begin{array}{l}1.2 \mathrm{MWh} / \mathrm{bdt} \text { pulp } \\
0.03 \mathrm{MWh} / \mathrm{bdt} \text { pulp }\end{array}$ & $\begin{array}{r}1.38^{\mathrm{b}} \mathrm{MWh} / \mathrm{bdt} \\
\text { pulp }\end{array}$ \\
\hline consumption & $3.0 \mathrm{~m}^{3} / \mathrm{bdt}$ pulp & $10.4 \mathrm{~m}^{3} / \mathrm{bdt}$ pulp \\
\hline $\begin{array}{lr}\text { Effluent } & \text { fibre poor } \\
& \text { fibre rich }\end{array}$ & $\begin{array}{l}3.8 \mathrm{~m}^{3} / \mathrm{bdt} \text { pulp } \\
5.5 \mathrm{~m}^{3} / \mathrm{bdt} \text { pulp }\end{array}$ & $\begin{array}{r}\text { wastewater } \\
2.5 \mathrm{~m}^{3} / \mathrm{bdt} \text { pulp }\end{array}$ \\
\hline
\end{tabular}

a including logging residues, bark, bio-sludge and reject fibres; see Fig 1.

$\mathrm{b}$ in $\quad 1.38(2.0 \mathrm{t} / \mathrm{bdt}$ pulp $)=1.32(2.5 \mathrm{bar})+0.06(100 \mathrm{bar})$;

out $\quad 2.0 \mathrm{t} / \mathrm{bdt}$ pulp $=0.2$ (to the air) +1.8 (condensed).

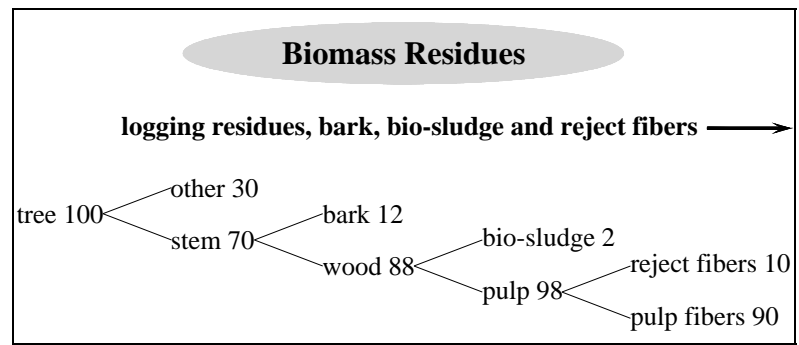

Fig 1. Available biomass residues for a TMP mill. 


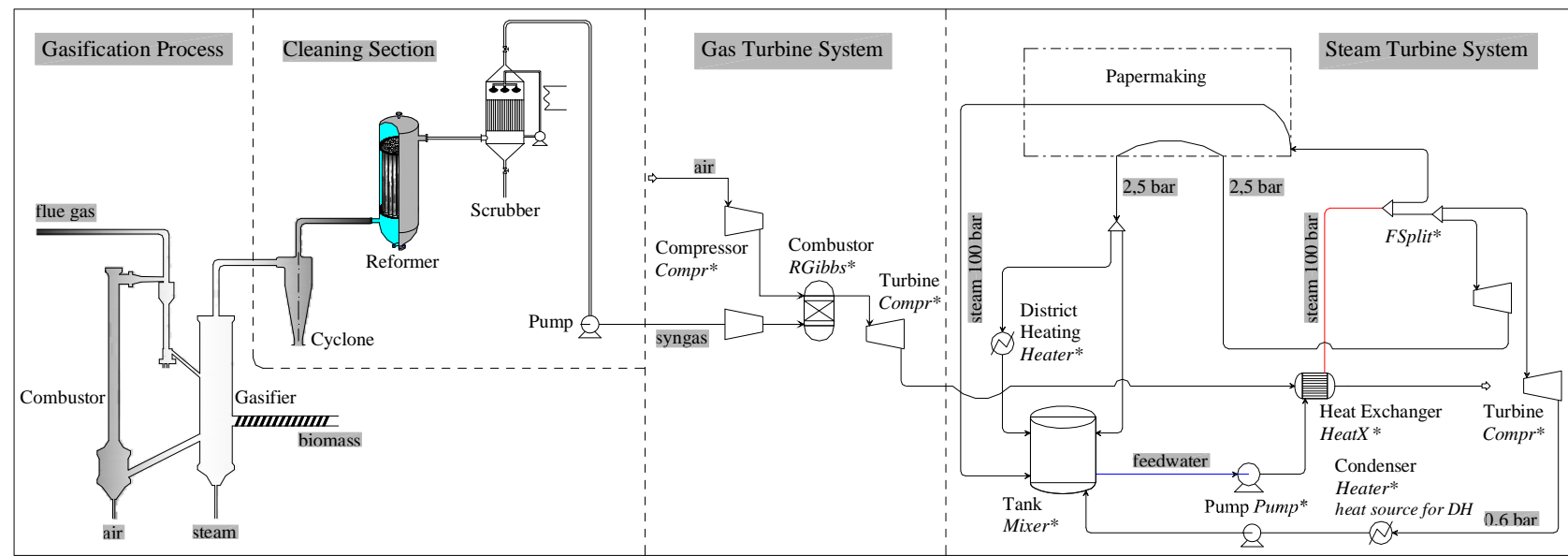

Fig 2. Flowsheet of a BIGCC model ( ${ }^{\star}$ ASPEN Plus module; DH---District Heating).

It is advantageous to apply the gasifier. The main advantages are that the gasifier can easily process various solid fuels, including high moisture biomass, and that the biomass pre-treatment is fairly simple (Zhang 2010). The details can be found in the literature (Göransson et al. 2011; He et al. 2012).

A detailed study on syngas cleaning was made by Göransson et al (2011). Eriksson and Kjellström (2010) suggested that the investment for a separate gasifier and gas cleaning unit amounts to about $25 \%$ of the CHP investment.

The cleaned syngas will be combusted to generate electricity through a gas turbine system. The exhausted high temperature flue gas flows through a heat exchanger. The steam $\left(100\right.$ bar $\left.565^{\circ} \mathrm{C}\right)$ can be therefore afforded, and expands through a steam turbine cycle from 100 bar to 0.6 bar to generate extra electricity. Simultaneously, a certain amount of 2.5 bar steam is withdrawn to PM. Besides, the 2.5 bar steam from TMP has been provided to PM.

For comparison, TMP+Boiler and $\mathrm{TMP}+\mathrm{CHP}$ are also modeled, respectively. The available amount of heat energy for a district heating (DH) system is calculated with the model. Additionally, for the TMP+Boiler case, it is assumed that $50 \%$ of the energy after the production of steam is utilized in DH. Table 2 lists the model input data.

\section{Simulation with ASPEN Plus}

ASPEN Plus is an excellent modeling tool which is versatile and relatively easy to use. It can be used to model complicated chemical engineering systems. It includes many model blocks to simulate various unit operations. If more sophisticated block ability is required, additional information will be added into the block in a form of FORTRAN subroutines, or an entirely new user block can be created.

The BIGCC model (see Fig 2) is set up with several ASPEN Plus modules. Each module simulates a unit process. The electricity generation efficiency of BIGCC depends on the efficiencies of gasification, compression, combustion, expansion, etc. The input data are collected from a variety of sources including experimental and literature data. The mass balance and energy balance are verified.
A compressor or a turbine is simulated with a module "Compr" which can calculate the power consumed or produced when the pressure ratio, isentropic, polytropic, and mechanical efficiencies, and clearance volume are given.

The combustor is modeled as a reactor in ASPEN Plus with the module "RGibbs" which executes equilibriums calculations by Gibbs free energy minimization. When a system does not reach a complete equilibrium state, "RGibbs" can also be used by additionally specifying an extent of equilibrium.

The heat exchanger is simulated with the module "Heatx", the pump with the module "Pump", and the flow splitter "FSplit".

Table 2. Model input data (Göransson et al., 2011; He et al., 2012).

\begin{tabular}{|c|c|c|c|}
\hline \multicolumn{2}{|c|}{ LHV Biomass } & {$[\mathrm{MJ} / \mathrm{kg}]$} & 18.0 \\
\hline Efficiency & $\begin{array}{r}\text { gasification } \\
\text { combustion } \\
\text { boiler } \\
\mathrm{DH}\end{array}$ & {$[\%]$} & $\begin{array}{l}80 \\
99 \\
75 \\
50^{\text {a }} \text { (for TMP+Boiler) }\end{array}$ \\
\hline Syngas & composition & $\begin{array}{l}\text { [vol.\%] } \\
{[\mathrm{MJ} / \mathrm{kg}]}\end{array}$ & $\begin{array}{l}1.1 \\
\mathrm{H}_{2} 37.5, \mathrm{CO} 35.0, \mathrm{CO}_{2} \\
15.0 \\
\mathrm{CH}_{4} 8.0, \mathrm{C}_{2} \mathrm{H}_{4} 0.5 \text { and } \\
\mathrm{N}_{2} 4.0 \\
13.2\end{array}$ \\
\hline Flue Gas & & {$\left[{ }^{\circ} \mathrm{C}\right]$} & $120^{b}$ \\
\hline $\begin{array}{l}\text { Working } \\
\text { Steam }\end{array}$ & & $\begin{array}{c}{[\mathrm{bar}]} \\
{\left[{ }^{\circ} \mathrm{C}\right]}\end{array}$ & $\begin{array}{l}100 \text { bar and } 565^{\circ} \mathrm{C} \\
100 \text { bar to } 0.6 \text { bar } \\
\text { (through a steam } \\
\text { turbine cycle) }\end{array}$ \\
\hline $\begin{array}{l}\text { Steam } \\
\text { (PM) }\end{array}$ & & [bar] & 2.5 \\
\hline \multicolumn{4}{|c|}{$\begin{array}{l}\text { a DH = (energy content of biomass - energy content of steam } \\
\text { (steam from the boiler to TMP+PM) }) \times 0.5 \\
\text { b The hot inlet-cold outlet temperature difference is set as } \\
209.6^{\circ} \mathrm{C} \text { for a submodel of a heat exchanger connecting a gas- } \\
\text { and steam-turbine cycles. }\end{array}$} \\
\hline
\end{tabular}


Table 3. Data for economic analysis (Eriksson, Kjellström 2010; Holmberg, Gustavsson 2007b; Pettersson 2005; Wetterlund, Söderström 2010)

\begin{tabular}{l|l}
\hline Operation Time & 8000 hr/yr \\
Power Generation Efficiency & $\begin{array}{l}44 \% \text { (calculated, BIGCC) } \\
28 \% \text { (calculated, CHP) }\end{array}$ \\
\hline & 3000 EUR/KWel (CHP) \\
2300 EUR/KWel (BIGCC) \\
Capital Investment & 710 EUR/t \\
& 80 EUR/MWh \\
\hline Paper & $0.07 \times$ the total capital investment \\
Heat & 50 EUR/MWh \\
O \& M Cost & 30 EUR/MWh \\
Electricity & 20 EUR/MWh \\
Electricity Certificate & $10 \quad$ EUR/MWh (the logging \\
Pulpwood & residues) \\
Biomass to BIGCC & 0 EUR/MWh (the TMP residues) \\
& 30 years \\
\hline Plant Lifespan & 10 years \\
Discounted Payback Period & \\
Annual Depreciation & DDB (factor 1.5) \\
the first 10 years & Straight-line Depreciation \\
the next 20 years & 0 \\
Profit Tax Rate & 0.1 \\
Discount Factor & \\
\hline
\end{tabular}

The accessed equations and data are "packaged" in a specific Property Method set in ASPEN Plus. The involved substances and operation conditions are crucial in choosing a proper Property Method. In modeling the gas turbine system, the Property Method PR-BM is adopted, and for the steam turbine system, the Property Method STEAM-TA is employed.

The ASPEN Plus function block "Design Spec" is auxiliarily applied to predict how much steam can be produced from the heat exchanger. In essence, it is a multi-objective optimum design method adopted. The 100 bar, $565^{\circ} \mathrm{C}$ steam is targeted to be produced. Simultaneously, the temperature of the flue gas is set to be $120^{\circ} \mathrm{C}$. The manipulated variable is "MASS-FLOW" (flowrate, $\mathrm{kg} / \mathrm{s}$ ). Similarly, for simulating the distribution of steam (by "FSplit"), the function block is also employed. The original stream of steam will be divided into two parts. In optimization, the target value is the known amount of 2.5 bar steam used in PM. The manipulated variable is "FLOW/FRAC" (stream fraction). Some details of the model can be found elsewhere (He 2012).

\section{Economic evaluation}

The economic profitability of TMP+BIGCC is evaluated in terms of the net revenue (after subtracting the depreciation) and IRR. IRR is also called the discounted cash flow rate of return or the rate of return. IRR disregards the absolute amount of money to be gained, and is an indicator of the efficiency, quality, or yield of an investment. An investment is considered acceptable if its IRR is higher than an established minimum acceptable IRR, 0.1 for instance. Generally, the higher the IRR, the better the investment.

Table 3 lists the data on this economic evaluation. The electricity generation efficiency of BIGCC or CHP is calculated from the model. For a TMP+PM mill, its capital investment is about $1920 \mathrm{EUR} / \mathrm{tpy}$ in a given paper production capacity (Holmberg, Gustavsson 2007b). The capital investment for BIGCC is $2300 \mathrm{EUR} / \mathrm{KWel}$ (Wetterlund, Söderström 2010). The capacity of power generation is about $30 \mathrm{MWel}$. The prices for some facilities are referred to the literature (Eriksson, Kjellström 2010; Phillips et al. 2007). The operation and maintenance cost accounts for $7.0 \%$ of the capital investment of a combined TMP+BIGCC mill. Electricity is purchased at about $50 \mathrm{EUR} / \mathrm{MWh}$. An electricity certificate credit of $30 \mathrm{EUR} / \mathrm{MWh}$ is taken into account. The price of pulpwood is $20 \mathrm{EUR} / \mathrm{MWh}$. The discounted payback period is set as 10 years. Available raw biomass materials from a TMP mill are free of charge. The overall cost for the logging residues is 10 EUR/MWh in synergy with pulpwood harvesting. The heat is sold at 80 EUR/MWh for DH. The plant lifespan is anticipated to be 30 years. In sensitivity analysis, the pulpwood is priced at 20 or 40 EUR/MWh, and the electricity at, 50 or 100 EUR/MWh. The other values are unchanged.

Two depreciation methods are adopted: for the first 10 years the Double-Declining Balance method (DDB), and for the next years the Straight-line Depreciation Method. Tax is not added. The economic analysis routine is programmed with Excel.

\section{Results and Discussion}

\section{Implementation of BIGCC in a TMP mill}

The energy balance over the BIGCC (or Boiler or CHP) process is studied by applying the model. Table 1 shows how much biomass can be available. The TMP+PM required steam is from the TMP and BIGCC, Boiler, or $\mathrm{CHP}$ processes. The total steam demand is kept constant because of the constant paper throughput. The enhancement of refining efficiency lowers the steam yield from TMP. Moving out the reject fibres also facilitates the reduction of TMP SEC. Less steam from TMP aggravates the steam supply from BIGCC (BIGCCa $=\mathrm{CHP}=$ Boiler $<$ BIGCCb $<$ BIGCCc $<$ BIGCCd $<$ BIGCCe). The model is designed to ensure that the steam consumption is sufficiently satisfied, as the results indicate (Fig 3). For the TMP+PM mill studied, the TMP SEC is about $2.5 \mathrm{MWh} / \mathrm{bdt}$ pulp, the PM SEC is about $0.75 \mathrm{MWh} / \mathrm{bdt}$ pulp, and the steam consumption is about 1.38 MWh/bdt pulp.

Compared with CHP, BIGCC has a higher electricity generation efficiency of $44 \%$. As a result, by implementing the BIGCC system in a TMP mill, less electricity will need to be purchased, and less when the TMP SEC is reduced, and even less when the reject fibres material is taken into account (BIGCCa > BIGCCb > BIGCCc > BIGCCd > BIGCCe) (Fig 3).

The electricity generation efficiency of a full-scale BIGCC plant can approach to 50\%. A BIGCC plant associated with a TMP+PM mill needs to supply PM steam, which lowers the electricity generation efficiency. As shown in Fig 3, for a BIGCC system, intensifying the steam supply weakens its electricity yield. For instance, for the steam supply, the sequence is BIGCCb < BIGCCc (or BIGCCd < BIGCCe), while for the electricity 


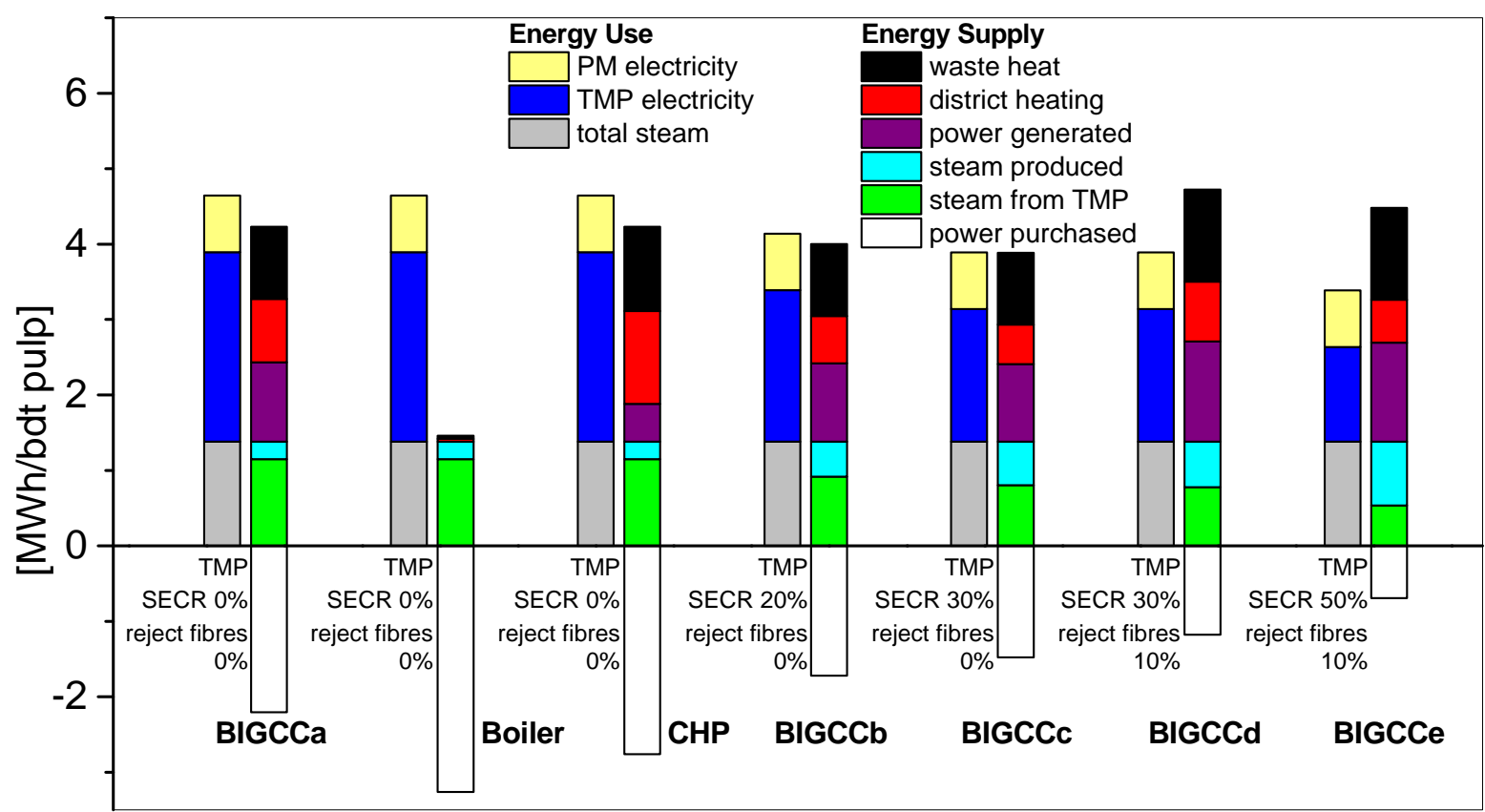

Fig 3. TMP energy use and supply.

(Three processes (BIGCC, Boiler, and CHP) are modeled respectively, and compared. The usable biomass, about $3.1 \mathrm{MWh} / \mathrm{bdt}$ pulp, includes the logging residues, bark, and bio-sludge, and is about $3.9 \mathrm{MWh} / \mathrm{bdt}$ pulp, further including the reject fibres (10 wt.\%). The energy contents of steam, electricity, heat for $\mathrm{DH}$, and energy loss equal to the total energy content of biomass. For the Boiler case, only a proper amount of biomass, about $0.3 \mathrm{MWh} / \mathrm{bdt}$ pulp, is consumed to produce the required steam. The paper yield will be kept by adding more pulpwood, though the reject fibres are moved out. Moving out the reject fibres makes the TMP more energy-efficient, i.e., the TMP SEC is reduced. Noticeably, a present target is SECR 50\%. The PM SEC is kept because of the constant paper throughput, while for the TMP SEC, the sequence is $\mathrm{BIGCCa}=\mathrm{CHP}=$ Boiler $>\mathrm{BIGCCb}>\mathrm{BIGCCC}=\mathrm{BIGCCd}>\mathrm{BIGCCe}$. The model is designed to ensure that the steam consumption is sufficiently satisfied, as the results show in the graph. The results demonstrate that the BIGCC process is the most efficient of the processes studied (BIGCCa > CHP > Boiler), and therefore, by implementing the BIGCC system in a TMP mill, less electricity will need to be purchased, and less when the TMP SEC is reduced, and even less when the reject fibres material is taken into account (BIGCCa > BIGCCb > BIGCCC > BIGCCd > BIGCCe).

generation efficiency, the sequence is reversed, i.e., BIGCCb > BIGCCc (or BIGCCd > BIGCCe).

The residual low-grade energy from the BIGCC (or Boiler or CHP) process is utilized in DH (Table 2). For the TMP+BIGCC cases, the available heat energy for DH drops with the decreasing of TMP SEC (available heat for DH: BIGCCb > BIGCCc; BIGCCd > BIGCCe). Two levels of turbine sets are respectively adopted, a high (from 100 bar to 2.5 bar) and a low (from 100 bar to 0.6 bar) pressure levels (Fig 2). The most heat energy for DH is from the condensing of the discharged 0.6 bar steam (latent heat). As aforementioned, as the TMP SEC falls, a greater part of the original 100 bar steam will be distributed to the 2.5 bar level turbine set. As a result, the usable latent heat is discounted.

\section{Additional biomass}

Biomass heat and power plants scaled up to 100 MW (in biomass energy input) have been popular in Sweden as well as other forest-rich countries. Forest logging residues, peat, biomass from short rotation forestry, and some industrial and household wastes, etc. are all available resources that can be taken as feedstock to BIGCC plants. Electricity consumed in a TMP mill can be fully afforded by a BIGCC plant without difficulty concerning biomass availability.
As indicated by the thick solid line in Fig 4a, the electricity supply from BIGCC, increasing with the amount of biomass used, tends to meet the TMP+PM consumption when about 9.4 MWh biomass per tonne of pulp is used. However, a great amount of heat is also generated along with the electricity production. This huge supply of low-grade energy must be directed to other uses such as DH. As clearly shown in Fig 4, BIGCC yields much more electricity and much less heat than CHP.

Fig $4 c$ and $4 d$ show that both the net revenue and the IRR increase significantly with the amount of biomass, and increase faster as the electricity price gets higher. The economic profitability of a TMP mill is more sensitive to the electricity price when a smaller amount of biomass is available to be fed into the gasifier, but is more sensitive to the pulpwood price when a larger amount of biomass is available to be fed into the gasifier (Fig $4 c$ and $4 d$ ). The electricity certificate instrument is an effective incitement, and directly adds 30 EUR per MWh electricity produced from biomass to the net revenue of the TMP+BIGCC or TMP+CHP mill. It is more profitable to invest in BIGCC than in CHP when more biomass is used for heat and power production. Plant scale and electricity price are two strong factors for the implementation of BIGCC in a TMP mill. 

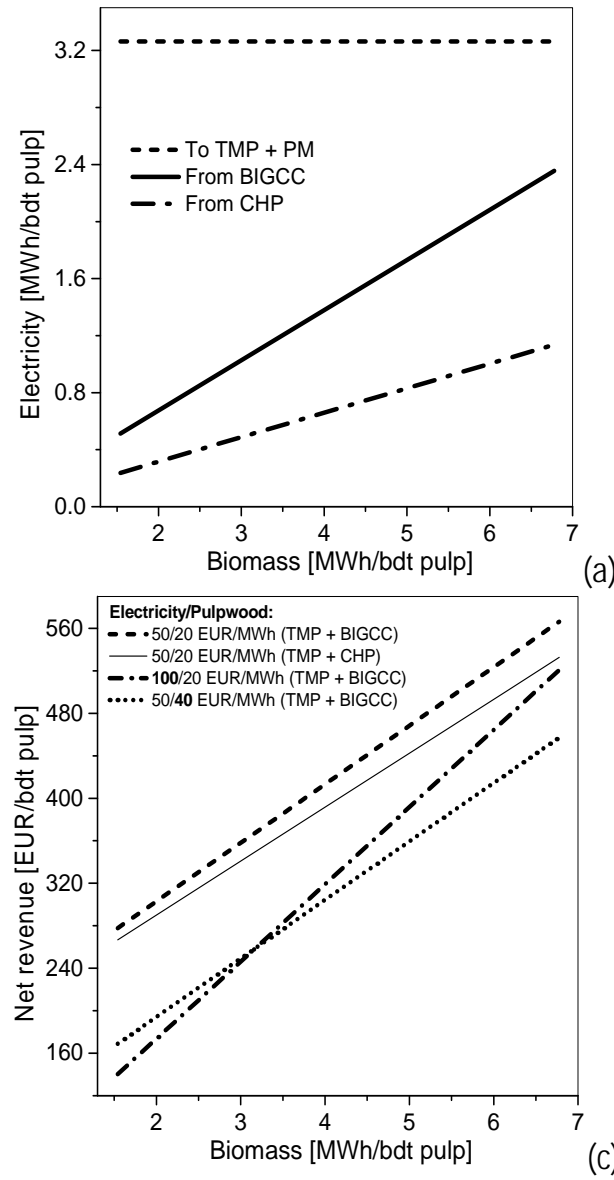

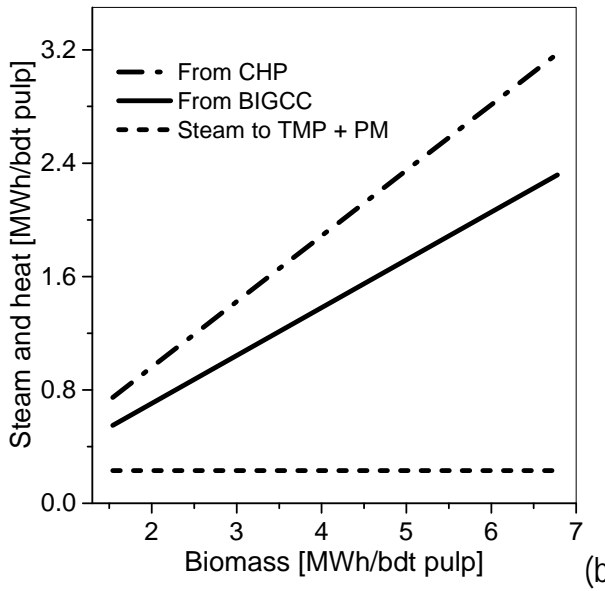

(b)

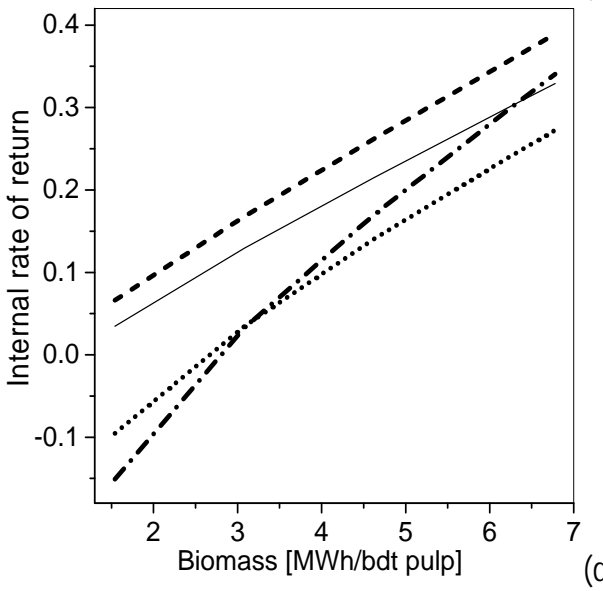

(d)

Fig 4. Effect of the amount of biomass.

(The electricity supply from BIGCC increases with the amount of biomass used, and tends to meet the TMP+PM consumption when about 9.4 MWh biomass per tonne of pulp is used (a). BIGCC produces much more electricity and much less heat than CHP (a and b). Both the net revenue and the IRR increase significantly with the amount of biomass, and increase faster with the rising electricity price (c and d). The economic profitability of a TMP mill is sensitive to both the electricity and the pulpwood prices (c and d). It will be more profitable to invest in BIGCC than in CHP if more biomass materials are used for heat and power production (c and d).)

\section{Reject fibres to gasifier}

Usually in TMP mills, up to about $10 \%$ of the pulp fibres have properties that are not good enough to remain in the final product, and they may be removed as reject fibres. The reject fibres can be utilized as feedstock to biomass gasifiers. 20\% TMP SECR should be possible when taking out the $10 \%$ worst fibre material with respect to final paper product properties (Westermark and Capretti, 1988).

As seen in Fig 5a, the electricity yield from BIGCC slightly increases with the amount of reject fibres, but is far from the TMP+PM electricity consumption denoted by the dashed line. The electricity yield of BIGCC has been twice more than that of CHP.

The y-axis in Fig $5 b$ represents the amount of steam and heat produced, including steam from BIGCC to $\mathrm{TMP}+\mathrm{PM}$, and heat from BIGCC to DH. The amount gets up as more reject fibres are transferred to the gasifier. Lower TMP SEC will lead to less steam supply from TMP. As a result, the heat and power plant needs to supply more steam. Obviously, CHP gives more steam and heat than BIGCC as much less electricity is generated by CHP.

Normally, the prices of electricity and pulpwood are 50 and 20 EUR/MWh, respectively (Fig $5 c$ and 5d). Both the net revenue and the IRR values increase with the amount of the reject fibres. This can be explained by several factors: 1) more electricity is generated as more reject fibres are added; 2) the TMP SEC is cut down; 3) the paper yield is held by supplementing pulpwood. Both the net revenue and the IRR values of TMP+BIGCC are much higher than those of TMP+CHP, as shown in Fig $5 c$ and $5 d$. This is because BIGCC produces much more electricity than CHP for the same amount of biomass residues, and has a lower specific investment cost than CHP (see Table 3). An increase in the market electricity price from 50 to $100 \mathrm{EUR} / \mathrm{MWh}$ obviously reduces the net revenue, as shown by the dash-dot line in Fig $5 c$. The economic profitability is sensitive to both the electricity and the pulpwood prices (Fig $5 c$ and $5 d$ ).

\section{Improved electric energy efficiency of the TMP-line}

As discussed above, TMP SEC is a key factor in the high cost pulp production. A 50\% SECR is targeted. The SECR is indicated by a dashed line in Fig 6a. The TMP+PM electricity consumption cannot be fully made up by the electricity supply from BIGCC, even if the TMP SEC goes down by 50\%. But the gap becomes fairly small, and much smaller in comparison with the case of CHP. Since a certain amount of 2.5 bar steam is 
withdrawn from BIGCC, the electricity generation efficiency of the steam turbine cycle will be lowered, which gives rise to a slightly lower electricity yield from BIGCC, as seen in Fig $6 a$.

The steam supply by TMP is impaired with the SECR. The margin must be supplemented by BIGCC (or CHP). A resulted increase in the steam and heat from BIGCC (or CHP) can be observed from Fig 6b. In some TMP+PM mills, a backup boiler is specially used to supply steam without self-production of electricity. In the TMP+Boiler case, a proper amount of biomass will be fed into for offering PM a certain amount of steam. As observed from the inset figure in Fig 6b, the boiler needs more biomass as the SEC declines, and the available biomass (bark + bio-sludge) within the TMP mill will no longer be enough when the SEC is decreased by more than $34 \%$. By further accumulating the reject fibres, it becomes sufficient.

As shown in Fig $6 c$ and 6d, lower TMP SEC leads to higher economic profit in both the net revenue and the IRR. For both the net revenue and the IRR, TMP+BIGCC $>\mathrm{TMP}+\mathrm{CHP}>\mathrm{TMP}+$ Boiler. This is mainly attributed to the lower specific investment cost in BIGCC. The investment of BIGCC is expected to be further decreased with more research and development towards the commercialization of BIGCC technology. So far, the

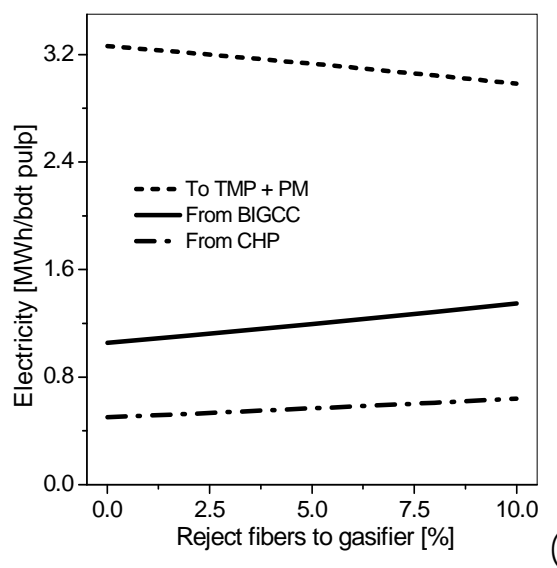

(a)

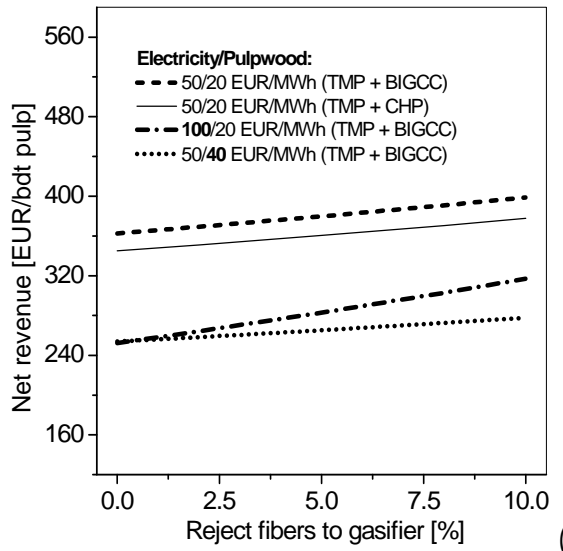

BIGCC technology has not been fully commercialized. Risks exist when BIGCC is implemented to the industries, including the pulp and paper industry.

In this evaluation, the heat price is assumed to be 80 EUR/MWh higher than the electricity price of 50 EUR/MWh. This assumption is in line with the current situation in Sweden that low tax is put on the electricity for industrial use and high tax for domestic use. In the long run, the electricity price for industrial use is reasonably going over the price of heat.

In the case that the electricity price for industries is the same as that for residential use in Sweden, about $150 \mathrm{EUR} / \mathrm{MWh}$, the IRR of a TMP mill will drop below about $-25 \%$, but for a TMP+BIGCC plant, the IRR can rapidly be raised to a positive value, depending on how much biomass residues will be used for electricity production.

Both the pulpwood and the electricity prices are key factors in determining the economic profitability of a TMP mill, as estimated by the model. In the Swedish market, solid biofuels and pulpwood have fairly stable low prices, while the electricity price is rather volatile. It can be said from practical viewpoint that the economic profitability of a TMP mill is dominated by the electricity price.

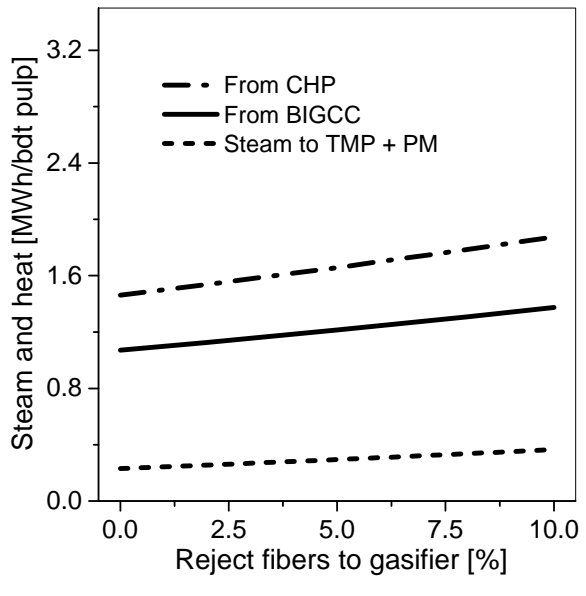

(b)

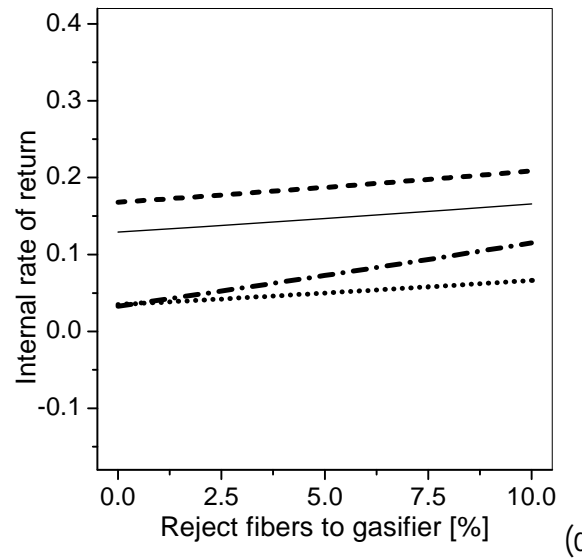

(d)

Fig 5. Effect of adding reject fibres.

(BIGCC produces twice more electricity than CHP, but the supply is still far from the TMP+PM consumption (a). Both BIGCC and $\mathrm{CHP}$ can afford TMP+PM sufficient steam (b). Both the net revenue and IRR increase with the amount of reject fibres (c and d). Both the net revenue and the IRR values of TMP+BIGCC are much higher than those of TMP+CHP, respectively, and the gap becomes bigger when more reject fibres are used ( $c$ and $d$ ). The economic profitability is dominated by both the pulpwood and the electricity prices (c and d).) 


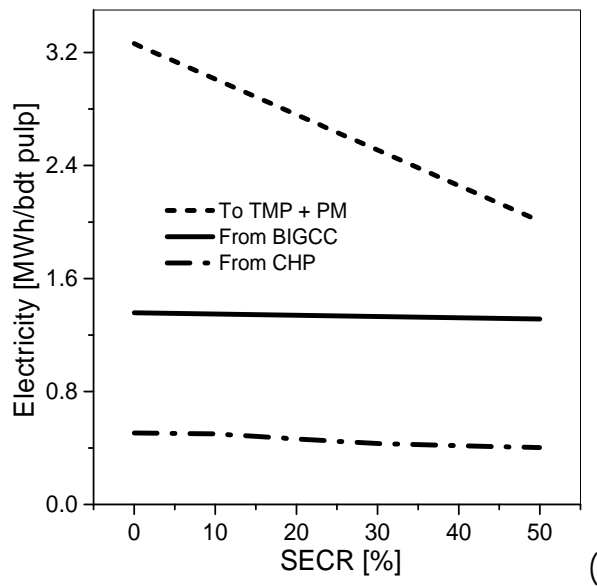

(a)
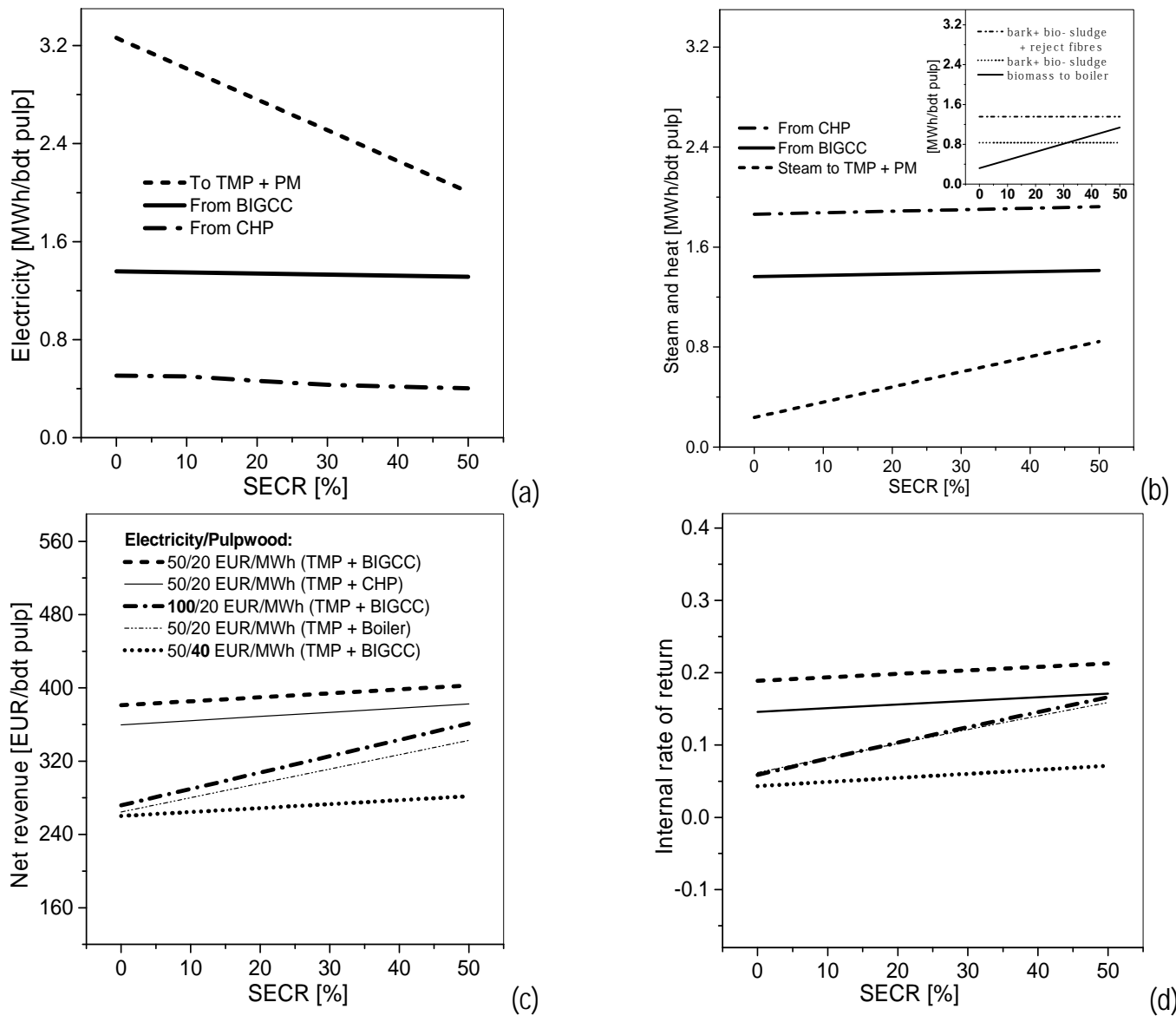

Fig 6. Effect of reducing the TMP-specific electricity consumption.

(The TMP+PM electricity consumption cannot be fully made up by the electricity supply from BIGCC, even if the TMP SEC goes down by $50 \%$. However, the gap becomes fairly small, and much smaller in comparison with the case of CHP (a). With the decreasing of SEC, less steam can be supplied from TMP. BIGCC (or CHP) must make up the balance (b). Lower TMP SEC leads to higher economic profit ( $c$ and d). For both the net revenue and the IRR, TMP+BIGCC > TMP+CHP > TMP+Boiler ( $c$ and d). The economic profitability is dominated by both the pulpwood and the electricity prices at a lower SECR, and is mostly dominated by the pulpwood price at a higher SECR (c and d).)

\section{Conclusions}

A TMP+BIGCC mathematical model is developed with ASPEN Plus. By modeling, the techno-economic evaluation of the TMP+BIGCC mill is done in comparison with a TMP+CHP and TMP+Boiler mills.

The electricity yield of BIGCC has been more than double that of CHP. BIGCC has a lower specific capital investment than CHP, which results in a shorter discount payback period and higher IRR. It is more profitable to invest in BIGCC than in CHP when more biomass is used for heat and power production and when the market electricity price is higher. The economic profitability of a TMP mill is more sensitive to the electricity price than the pulpwood price in today's TMP industry when the SEC is high, and no BIGCC is used to provide TMP electricity. The profitability will be dominated by the pulpwood price when the SEC is low, and a great part of electricity to TMP is produced by an associated BIGCC plant. The plant scale and market electricity price are two strong factors determining the implementation of BIGCC in a TMP mill.
Both the net revenue and the IRR increase with the amount of the reject fibres, since more electricity is selfproduced on-site, the TMP SEC is reduced, and the paper output is held constant while more pulpwood is added. Rejection of low-quality pulp fibres and their reuse in BIGCC for self-production of electricity, and electricity certificate are highly attractive measures to raise the profitability of a TMP mill.

The TMP+PM electricity consumption cannot be fully made up by the electricity supply from a BIGCC plant, even if the TMP SEC goes down by $50 \%$. But the gap becomes fairly small, and much smaller in comparison with the case of a CHP plant. Lower TMP SEC leads to higher economic profit in both the net revenue and the IRR. The profits are ranked as: TMP+BIGCC > $T M P+C H P>T M P+$ Boiler .

\section{Acknowledgements}

The authors would like to acknowledge the project support of EU regional structure fund, Ångpanneföreningen Foundation for Research and Development, LKAB, Länsstyrelsen Västernorrland and Swedish Gasification Centre (SFC). Many helps from colleagues in the MIUN gasification group, Kristina Göransson, Ulf Söderlind and Lars Strömmer are appreciated. 


\section{Literature}

Berglin, N., and Berntsson, T. (1998). CHP in the pulp industry using black liquor gasification: thermodynamic analysis. Applied Thermal Engineering 18, 947-961.

Emun, F., Gadalla, M., Majozi, T., and Boer, D. (2010). Integrated gasification combined cycle (IGCC) process simulation and optimization. Computers \& Chemical Engineering 34, 331-338.

Engstrand, P., Jonsson, J., Sandberg, C., Starck, G. Wancke-Stähl, C., and Wahlgren, M. (2003). Method of producing bleached thermomechanical pulp (TMP) or bleached chemithermomechanical pulp (CTMP) (WO Patent WO/2003/000,982).

Engstrand, P.O., Htun, M.T., Hammar, L., and Pettersson, R.L. (1989). Method of reducing the energy consumption at the refining of cellulose-containing material (EP Patent 0,302,075).

Eriksson, G., and Kjellström, B. (2010). Assessment of combined heat and power (CHP) integrated with wood-based ethanol production. Applied Energy 87, 3632-3641.

Eriksson, H., and Harvey, S. (2004). Black liquor gasification consequences for both industry and society. Energy 29, 581 612.

Göransson, K., Söderlind, U., and Zhang, W.N. (2011). Experimental test on a novel dual fluidised bed biomass gasifier for synthetic fuel production. Fuel 90, 1340--1349.

Gorski, D., Hill, J., Engstrand, P., and Johansson, L. (2010). Review: reduction of energy consumption in TMP refining through mechanical pre-treatment of wood chips. Nord Pulp Pap Res J 25, 156-161.

Harvey, S., and Facchini, B. (2004). Predicting black liquor gasification combined cycle powerhouse performance accounting for off-design gas turbine operation. Applied Thermal Engineering 24, 111-126.

He, J. (2012). Gasification-based Biorefinery for Mechanical Pulp Mills. Licentiate thesis at the Department of Applied Science and Design (Sundsvall, Sweden, Mid Sweden University), pp. 63.

He, J., Göransson, K., Söderlind, U., and Zhang, W. (2012). Simulation of biomass gasification in a dual fluidized bed gasifier. Biomass Conversion and Biorefinery 2, 1-10.

Höglund, H., Bäck, R., Danielsson, O., and Falk, B. (1994). A method of producing mechanical and chemi-mechanical pulp (WO Patent 1,994,016,139).

Holmberg, J.M., and Gustavsson, L. (2007a). Biomass use in chemical and mechanical pulping with biomass-based energy supply. Resour Conserv Recy 52, 331-350.

Holmberg, J.M., and Gustavsson, L. (2007b). Systems aspects on new energy technologies in the pulp and paper industry. Paper presented at: 3rd International Green Energy Conference IGEC-III June 18-20, 2007 Västerås, Sweden.

Muhic, D., Sundstrom, L., Sandberg, C., Ullmar, M., and Engstrand, P. (2010). Influence of temperature on energy efficiency in double disc chip refining. Nord Pulp Pap Res J 25, 420-427.

Naqvi, M., Yan, J., and Dahlquist, E. (2010). Black liquor gasification integrated in pulp and paper mills: A critical review. Bioresource Technology 101, 8001-8015.

Naqvi, M., Yan, J., and Dahlquist, E. (2012). Synthetic gas production from dry black liquor gasification process using direct causticization with $\mathrm{CO}_{2}$ capture. Applied Energy 97, 4955 .

Norgren, S., and Höglund, H. (2009). Irreversible long fibre collapse at high temperature refining in a TMP system: Effects on fibre and surface properties. Nord Pulp Pap Res J 24, 19-24. Ong'iro, A., Ugursal, V.I., Al Taweel, A.M., and Lajeunesse, G. (1996). Thermodynamic simulation and evaluation of a steam CHP plant using ASPEN Plus. Applied Thermal Engineering 16, 263-271.

Ong'iro, A.O., Ugursal, V.I., Al Taweel, A.M., and Blamire, D.K. (1995). Simulation of combined cycle power plants using the ASPEN PLUS shell. Heat Recovery Systems and CHP 15, 105-113.

Pettersson, J. (2005). Energikartläggning för energiledningssystem-Holmen Paper, Hallsta (energy survey for energy management-Holmen Paper, Hallsta) (Luleå, Avdelningen för Energiteknik, Luleå Tekniska Universitet), pp. 166.

Phillips, S., Aden, A., Jechura, J., Dayton, D., and Eggeman, T. (2007). Thermochemical ethanol via indirect gasification and mixed alcohol synthesis of lignocellulosic biomass. NREL/TP510-411682007.

Ruohonen, P., and Ahtila, P. (2011). Qualitative analysis of a thermo mechanical pulp and paper mill using advanced composite curves. Energy 36, 3871-3877.

Sabourin, M. (1999). Method of pretreating lignocellulose fibercontaining material for the pulp making process (WO Patent 1,999,007,935).

Sundholm, J. (1999). Mechanical pulping (Helsinki, Fapet).

Westermark, U., and Capretti, G. (1988). Influence of ray cells on the bleachability and properties of CTMP and kraft pulps. Nord Pulp Pap Res J 3, 95-99.

Wetterlund, E., and Söderström, M. (2010). Biomass gasification in district heating systems-The effect of economic energy policies. Applied Energy 87, 2914-2922.

Zhang, W. (2010). Automotive fuels from biomass via gasification. Fuel Process Technol 91, 866--876.

Manuscript received December 12, 2012 Accepted June 27, 2013 